\title{
Fabrication and Electrical Characterization of Translucent $\mathrm{Bi}_{12} \mathrm{TiO}_{20}$ Ceramics
}

\author{
D. J. Santos, L. B. Barbosa, R. S. Silva, and Z. S. Macedo \\ Physics Department, Federal University of Sergipe, Road Marechal Rondon s/n, 491000-000 São Cristovão, SE, Brazil \\ Correspondence should be addressed to Z. S. Macedo; zelia.macedo@gmail.com
}

Received 27 March 2013; Revised 11 June 2013; Accepted 25 June 2013

Academic Editor: Victor V. Moshchalkov

Copyright (C) 2013 D. J. Santos et al. This is an open access article distributed under the Creative Commons Attribution License, which permits unrestricted use, distribution, and reproduction in any medium, provided the original work is properly cited.

The production of high-density $\mathrm{Bi}_{12} \mathrm{TiO}_{20}$ ceramics, their transmission spectrum, and impedance features are reported. The samples were synthesized at $700^{\circ} \mathrm{C} / 6 \mathrm{~h}$ and sintered at $800^{\circ} \mathrm{C} / 3 \mathrm{~h}$. This procedure yielded translucent ceramics with relative density of $99.2 \pm$ $0.5 \%$ and average grain size of $3.1 \pm 1.6 \mu \mathrm{m}$. Samples with $0.5 \mathrm{~mm}$ thickness were translucent with optical transmission of about $30 \%$ at $800 \mathrm{~nm}$. The electrical and dielectric properties of the high-density ceramics were studied and compared with those measured for samples with lower density and also with the literature about $\mathrm{Bi}_{12} \mathrm{TiO}_{20}$ single crystals. The activation energy for the conduction process in high-density ceramic was $0.99 \mathrm{eV}$, and the dielectric permittivity was 40 at $200^{\circ} \mathrm{C}$. These values are comparable to those reported for single crystals.

\section{Introduction}

Bismuth titanate $\left(\mathrm{Bi}_{12} \mathrm{TiO}_{20}-\mathrm{BTO}\right)$ crystallizes in a bodycentered cubic structure with $\mathrm{I} 23$ space group and two chemical formulas per unit cell. It belongs to a class of materials known as sillenites [1], which includes the isomorphs $\mathrm{Bi}_{12} \mathrm{SiO}_{20}, \mathrm{BSO}$, and $\mathrm{Bi}_{12} \mathrm{GeO}_{20}, \mathrm{BGO}$. These crystals have many interesting properties, including electrooptical and photoconductive ones [2-4]. The combination of these properties causes the so-called photorefractive effect that consists of a reversible light-induced change in the refractive index [4]. These features render sillenite-type crystals useful in a variety of advanced and potentially promising applications such as reversible recording media for realtime holography or image processing applications [2]. In comparison to BSO and BGO, BTO presents some practical advantages for technological applications, including a higher electrooptic coefficient and smaller optical activity $[5,6]$.

Transparency of photoconductive materials is a desirable feature since the photons must be transported efficiently to the absorption centers of the bulk material. In recent years, many efforts have been made to improve the transparency of polycrystalline materials aiming at the substitution of single crystals for several applications [7-10]. These works suggest that high density (low porosity) is necessary for transparency since the pores are very efficient scattering centers. Besides the optical quality, the electrical and dielectric properties of photoconductive polycrystals must be studied as well, so as to provide a better understanding of their electrical behavior and achieve the optimization of their properties. A material's conductivity depends on its overall characteristics, such as its chemical composition, purity, and microstructure. In this sense, impedance spectroscopy is a flexible tool for simultaneous electrical and dielectric characterization of materials, particularly for ceramics, since each microregion, as well as any electrode interface effects, has a distinct relaxation frequency as determined by this technique. The analysis of impedance data employs equivalent circuit analogous for each perceived physical mechanism [11, 12], which provides a physical representation of the relaxation process.

The aim of this work is to investigate the production and properties of high-density translucent $\mathrm{Bi}_{12} \mathrm{TiO}_{20}$ ceramics, comparing the electrical and dielectric parameters of these samples with those previously reported in the literature for single crystals. To achieve a comprehensive view of the problem, ceramic bodies with low density were also produced and used as reference. 


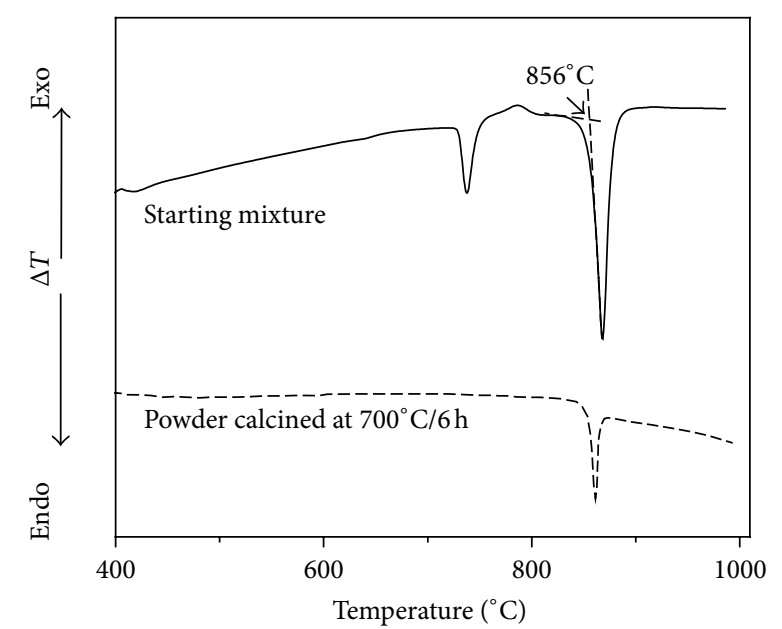

FIgURE 1: Differential thermal analysis (DTA) of the $\mathrm{Bi}_{2} \mathrm{O}_{3}-\mathrm{TiO}_{2}$ starting mixture (solid line) and calcined $\mathrm{Bi}_{12} \mathrm{TiO}_{20}$ (dashed line).

\section{Experimental}

The $\mathrm{Bi}_{12} \mathrm{TiO}_{20}$ single-phase powder was obtained by solidstate reaction. The precursor oxides used in stoichiometric proportion were $\mathrm{Bi}_{2} \mathrm{O}_{3}$ (Alfa Aesar, 99.99\%) and $\mathrm{TiO}_{2}$ (Merck, 99.9\%) in the 6:1 molar ratio. The raw materials were grounded in agate mortar for $20 \mathrm{~min}$ and then calcined at two different temperatures, as will be discussed in the following. Differential thermal analysis (DTA) was performed for both the starting mixture and synthesized powder, using an SDT 2960-TA Instruments equipment. These measurements were done at a heating rate of $10^{\circ} \mathrm{C} / \mathrm{min}$, in a flow of synthetic air $\left(\mathrm{O}_{2} / \mathrm{N}_{2}-1 / 4\right)$, from room temperature up to $1000^{\circ} \mathrm{C}$.

After the calcination, the powder was ground again in an agate mortar, mixed with a binder solution of polyvinyl alcohol with a $0.1 \mathrm{~g} / \mathrm{mL}$ concentration, and conformed by uniaxial pressing in pellets with relative green density of 61 $\pm 2 \%$. These pellets were heated up to $450^{\circ} \mathrm{C}$ for $30 \mathrm{~min}$ to eliminate polyvinyl alcohol and then sintered at different conditions to produce samples with different densities. The final density of the sintered ceramics was determined by using ASTM procedure C373 based on Archimedes' principle, as described in [13].

The structural and phase characterizations of the calcined powders and sintered ceramics were done by means of powder X-ray diffraction (XRD) in a Rigaku RINT 2000/PC, using $\mathrm{Cu} \mathrm{K} \alpha$ radiation. The measurements were performed at room temperature from $20^{\circ}$ to $80^{\circ}$, in steps of $0.02^{\circ}$, and acquisition time of $10 \mathrm{~s}$. The diffraction patterns were analyzed according to the Rietveld method.

Scanning electron microscope (JEOL JSM6510-LV) images were used to investigate the microstructure of the sintered ceramics and to determine the average grain size $(\bar{G})$ of the samples. For the porous samples sintered at 700 and $750^{\circ} \mathrm{C}$, the grain sizes were measured directly and averaged for 5 micrographs. For the dense samples sintered at $800^{\circ} \mathrm{C}$,
$(\bar{G})$ was determined by the intercept linear method, ASMT procedure E112-95 [14]. Optical transmission was measured from $350 \mathrm{~nm}$ to $1050 \mathrm{~nm}$ (spectrometer Ocean Optics HR 2000 , resolution of $0.5 \mathrm{~nm}$ ) at room temperature.

For the impedance spectroscopy measurements, the ceramic disks were polished with silicon carbide, cleaned with isopropyl alcohol in ultrasonic bath for 15 minutes, and dried at $100^{\circ} \mathrm{C}$. Electric contact was made by applying $\mathrm{Pt}$ paste on the parallel faces of the pellet and firing it at $700^{\circ} \mathrm{C}$ for 30 minutes. Impedance data were recorded in the frequency range from $1 \mathrm{~Hz}$ to $10 \mathrm{MHz}$ (Solartron 1260). The amplitude of the measuring AC signal was $2000 \mathrm{mV}$. It should be noted that the impedance modulus was not found to depend on the amplitude of the sinusoidal signal at any measuring temperature. This indicates that the recorded impedances are governed mainly by intrinsic electrical properties of $\mathrm{Bi}_{12} \mathrm{TiO}_{20}$ and that electrode polarization (in terms of resistance) can be neglected within the investigated temperature range. Isothermal impedance measurements were taken on a two-electrode configuration cell, in dry air, from room temperature to $700^{\circ} \mathrm{C}$, in $100^{\circ} \mathrm{C}$ steps.

\section{Results and Discussion}

Figure 1 presents the differential thermal analysis (DTA) curves of the mixed precursors, where one can observe two endothermic peaks with onsets at 730 and $856^{\circ} \mathrm{C}$. According to the phase diagram of the system $\mathrm{Bi}_{2} \mathrm{O}_{3}-\mathrm{TiO}_{2}$ in [15], the $\mathrm{Bi}_{12} \mathrm{TiO}_{20}$ phase melts incongruently at $875^{\circ} \mathrm{C}$, where it decomposes into $\mathrm{Bi}_{2} \mathrm{O}_{3}$ and $\mathrm{Bi}_{4} \mathrm{Ti}_{3} \mathrm{O}_{12}$. This peritectic point was observed at $865^{\circ} \mathrm{C}$ by [16] and at $855^{\circ} \mathrm{C}$ by [17], so the peak at $856^{\circ} \mathrm{C}$ in Figure 1 was associated with the incongruent melting of the samples. On the other hand, the thermal event observed at $730^{\circ} \mathrm{C}$ was interpreted as the crystallization of the $\mathrm{Bi}_{12} \mathrm{TiO}_{20}$ phase, so the calcination tests were carried out at 600 and $700^{\circ} \mathrm{C}$, whereas the sintering tests were performed for temperatures of 700,750 , and $800^{\circ} \mathrm{C}$. Considering that in muffle furnaces the experimental error and temperature fluctuations can be higher than those measured for the DTA furnace, the temperatures for the calcination and sintering tests were chosen to avoid the incongruent melting of the samples. The melting point of the $\mathrm{Bi}_{12} \mathrm{TiO}_{20}$ phase was further confirmed by the DTA curve of the calcined powder, also shown in Figure 1, where only the endothermic peak at $856^{\circ} \mathrm{C}$ can be observed.

Figure 2 presents the X-ray diffraction patterns of the powders calcined at 600 and $700^{\circ} \mathrm{C}$. Soaking times of 6 and $8 \mathrm{~h}$ were tested for both temperatures. It can be observed that the samples calcined at $600^{\circ} \mathrm{C}$ presented an unidentified phase, probably related to unreacted precursors or intermediate phases, whereas the samples produced at $700^{\circ} \mathrm{C}$ presented single phase for both soaking times used. Consequently, all the samples used in this work were calcined at $700^{\circ} \mathrm{C}$ for $6 \mathrm{~h}$.

The experimental XRD data were refined for the powders calcined at $700^{\circ} \mathrm{C}$ for $6 \mathrm{~h}$ and ceramics sintered at $800^{\circ} \mathrm{C} / 3 \mathrm{~h}$. Rietveld method was used, following a pseudo-Voigt model and departing from the lattice constants and atomic positions 


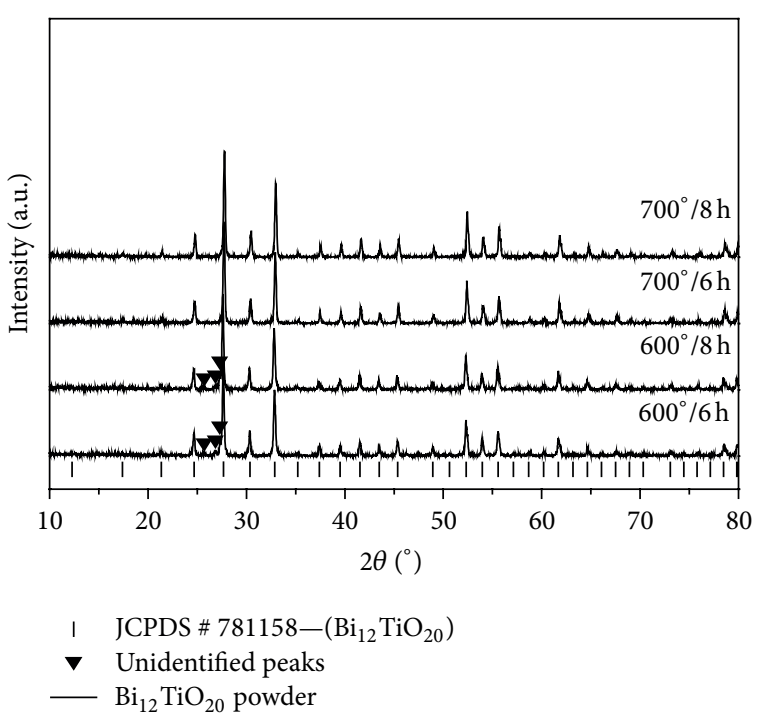

FIgURE 2: XRD data of $\mathrm{Bi}_{12} \mathrm{TiO}_{20}$ powder calcined under different experimental conditions.

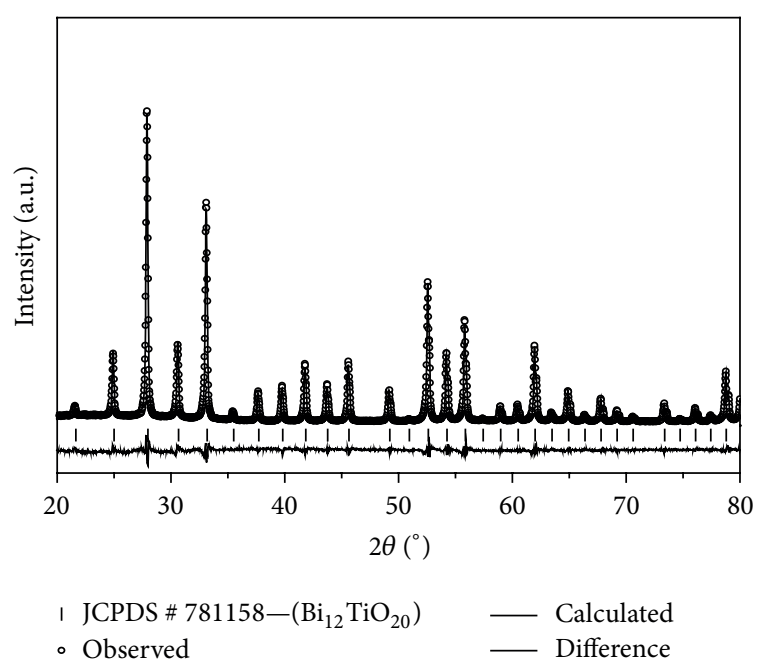

FIgURE 3: Plot output from the Rietveld refinement of the $\mathrm{Bi}_{12} \mathrm{TiO}_{20}$ ceramic sintered at $800^{\circ} \mathrm{C}$ for 3 hours. The dots represent the XRD data and the solid curve represents the calculated pattern. The difference plot is shown at the bottom of the graph.

of [18]. Figure 3 presents the refined pattern of ceramics, where one can observe that a quite good structural refinement was achieved. The values $R_{\mathrm{Bragg}}=7.18, R_{\mathrm{wp}}=9.94 \%$, and $R_{\text {exp }}=2.25 \%$ (for calcined powder) and $R_{\text {Bragg }}=6.68$, $R_{\mathrm{wp}}=10.47 \%$, and $R_{\text {exp }}=3.31 \%$ (for sintered ceramics) were achieved. These results have confirmed the cubic structure and spatial group I23 at room temperature, with cell parameters $a=b=c=10.1722 \pm 0.0001 \AA$ and $a=b=$ $c=10.1720 \pm 0.0002 \AA$ for calcined powders and sintered ceramics, respectively. The cell parameters obtained from the fittings are comparable to those reported in the literature [18].

Figure 4 presents SEM images of the samples sintered in air at 700,750 , and $800^{\circ} \mathrm{C}$ (heating rate of $10^{\circ} \mathrm{C} / \mathrm{min}$ )
TABLE 1: Relative density $\left(\rho_{\text {rel }}\right)$ and average grain size $(\bar{G})$ of BTO ceramics sintered at different conditions (see Figure 3 ).

\begin{tabular}{lccc}
\hline $\begin{array}{l}\text { Sintering } \\
\text { temperature }\left({ }^{\circ} \mathrm{C}\right)\end{array}$ & $\begin{array}{c}\text { Soaking time } \\
(\mathrm{h})\end{array}$ & $\rho_{\text {rel }}{ }^{*}(\%)$ & $(\bar{G})(\mu \mathrm{m})$ \\
\hline 700 & 0 & $65 \pm 1$ & $1.4 \pm 0.6$ \\
750 & 0 & $71 \pm 1$ & $1.5 \pm 0.6$ \\
800 & 0 & $96.9 \pm 0.5$ & $1.6 \pm 0.6$ \\
800 & 1 & $99.0 \pm 0.5$ & $2.2 \pm 1.0$ \\
800 & 2 & $99.2 \pm 0.5$ & $3.1 \pm 1.5$ \\
800 & 3 & $99.1 \pm 0.5$ & $3.1 \pm 1.6$ \\
\hline
\end{tabular}

${ }^{*} \rho_{\text {th }}=8.952 \mathrm{~g} / \mathrm{cm}^{3}[18]$.

with soaking times from zero to 3 hours. Table 1 presents the density and average grain size $(\bar{G})$ determined for these samples. As can be observed, the samples sintered at 700 and $750^{\circ} \mathrm{C}$ with no soaking time still remained in the initial stages of sintering, presenting low density and high porosity. By increasing the temperature, an increase in relative density is verified, up to $99.0 \pm 0.5 \%$ of the theoretical density $\left(8.952 \mathrm{~g} / \mathrm{cm}^{3}\right)$ for the samples sintered at $800^{\circ} \mathrm{C}$ for $1 \mathrm{~h}$. This density remained constant for longer soaking times at $800^{\circ} \mathrm{C}$, while the grains presented little growth from $(\bar{G})=2.2 \pm$ $1.0 \mu \mathrm{m}$ to $(\bar{G})=3.1 \pm 1.6 \mu \mathrm{m}$.

Figure 5(a) shows the sample sintered at $800^{\circ} \mathrm{C}$ for $3 \mathrm{~h}$, polished to the thickness of $0.5 \mathrm{~mm}$. As can be observed, the ceramic prepared at these conditions is translucent, confirming the low grain-boundary scattering of the incident light. The optical transmission of this sample is presented in Figure 5(b), where one can observe a broad transmission band starting at $450 \mathrm{~nm}$ and reaching 30\% between 800 and $950 \mathrm{~nm}$. Another band, superposed to the first one, rises rapidly for higher wavelengths up to $1050 \mathrm{~nm}$. A detailed study of the optical transmittance and its dependence on the grain size and density is being carried out in our research group and should be presented in a future work. Nevertheless, the results obtained up to the moment are very promising from the point of view of the possible applications of polycrystalline BTO in photoconductive devices. In this case, it is relevant to investigate how the grain boundaries modify the conductive and dielectric response of the material. In some cases in which grain boundaries present lower conductivity than the intragrain region, spatial charges may pile up in the interfaces leading to a Maxwell-Wagner relaxation that modifies the overall permittivity $[11,19]$. To avoid these space charges effects, it is desirable to obtain grain boundaries with electrical features similar to those of intragrain region.

It is well known that the electric and polar properties of single-phase ceramics are sensitive to the microstructure [20]. For a more in-depth investigation into the nature of this dependence, impedance spectroscopy measurements were performed for BTO samples with low and high densities. The correspondent Nyquist diagrams are presented in Figure 6 for the measurements taken at $500^{\circ} \mathrm{C}$. The samples with low density of $65 \%$ present two well-resolved semicircles, corresponding to the impedance of grains ( $\mathrm{g}$ ) and grain boundaries (gb) towards, respectively, high and low frequencies. The 


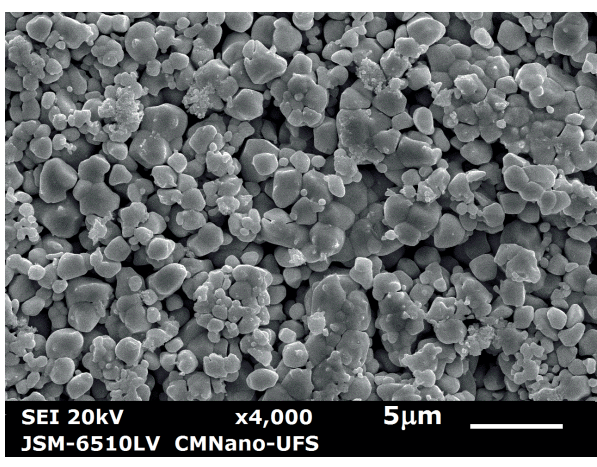

(a)

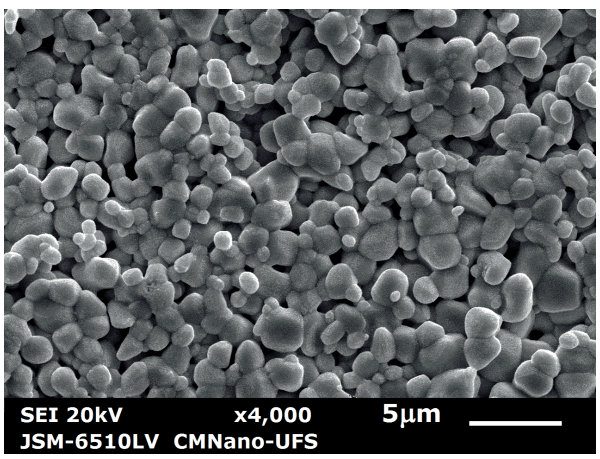

(c)

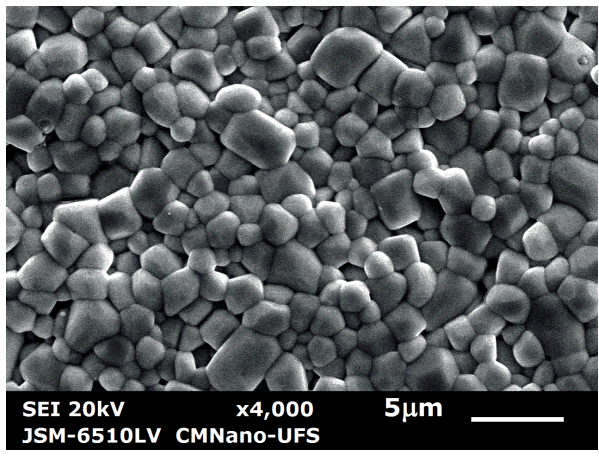

(e)

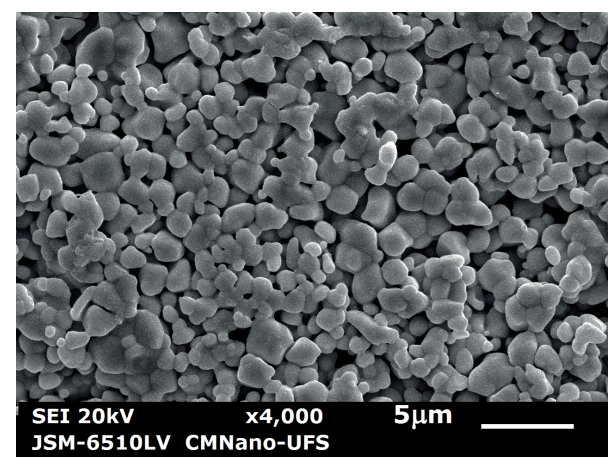

(b)

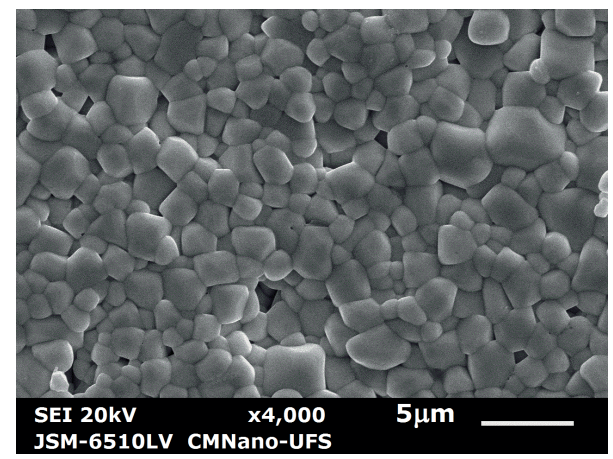

(d)

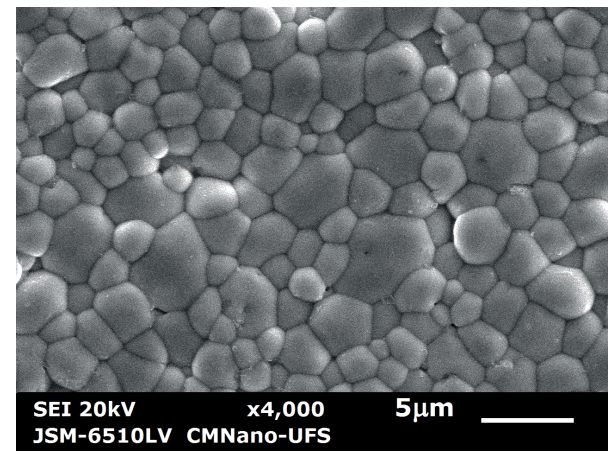

(f)

FIGURE 4: Representative SEM images of BTO ceramics sintered at (a) $700^{\circ} \mathrm{C}$, (b) $750^{\circ} \mathrm{C}$, and (c) $800^{\circ} \mathrm{C}$, without soaking time, and at $800^{\circ} \mathrm{C}$ for (d) $1 \mathrm{~h},(\mathrm{e}) 2 \mathrm{~h}$, and (f) $3 \mathrm{~h}$. The density and grain size of each sample are presented in Table 1 .

electrical resistivity of each region is characterized by the diameter of the corresponding normalized semicircle, and the maximum of each semicircular arc corresponds to the relaxation frequency $\omega=1 / R C$. From the diameters of the semicircles, it can be noticed that the grain boundaries of the porous ceramic are more resistive than the intragrain region. On the other hand, the high-density sample presented much smaller resistivity of grain boundaries and semicircles that are strongly superposed, meaning that the contributions from the two microstructural regions occur at very close frequencies. It can also be noticed that the intragrain semicircles of both samples have comparable relaxation frequencies. It was possible to separate the contributions from grain and grain boundaries of the low-density ceramic using equivalent circuits and brick-layer model $[11,13]$. The equivalent circuit normally used to fit such results consists of two parallel resistance-capacitance $(R C)$ blocks arranged in series. For the high-density ceramics, the two contributions could not be separated, so the equivalent circuit consisted of only one $R C$ block. The circuit models used are illustrated in Figure 6, as well as the overall fitting curves obtained in each case. As can be observed, the experimental response was in excellent agreement with the theoretical one thus indicating that the proposed model gave an adequate representation of the electrical properties of the samples. It was not necessary to include an impedance element representing the ceramicelectrode interface in this case since the contact impedance was small.

From the resistance $(R)$ values obtained from the fittings, it was possible to calculate ac conductivity $(\sigma)$. Figure 7 shows 


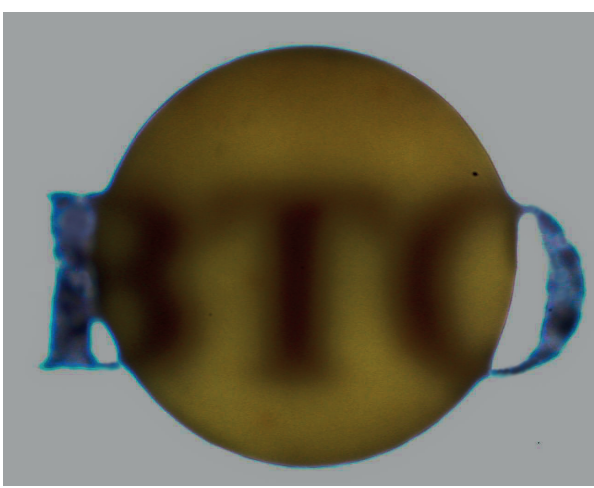

(a)

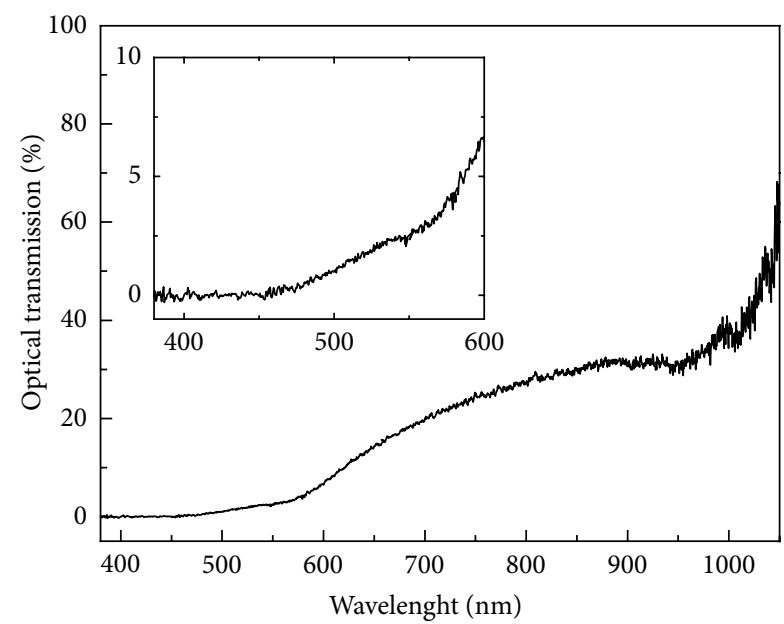

(b)

FIgURE 5: (a) BTO ceramics sintered at $800^{\circ} \mathrm{C} / 3 \mathrm{~h}$ and polished to the thickness of $0.5 \mathrm{~mm}$. (b) Transmission spectra of the sample.

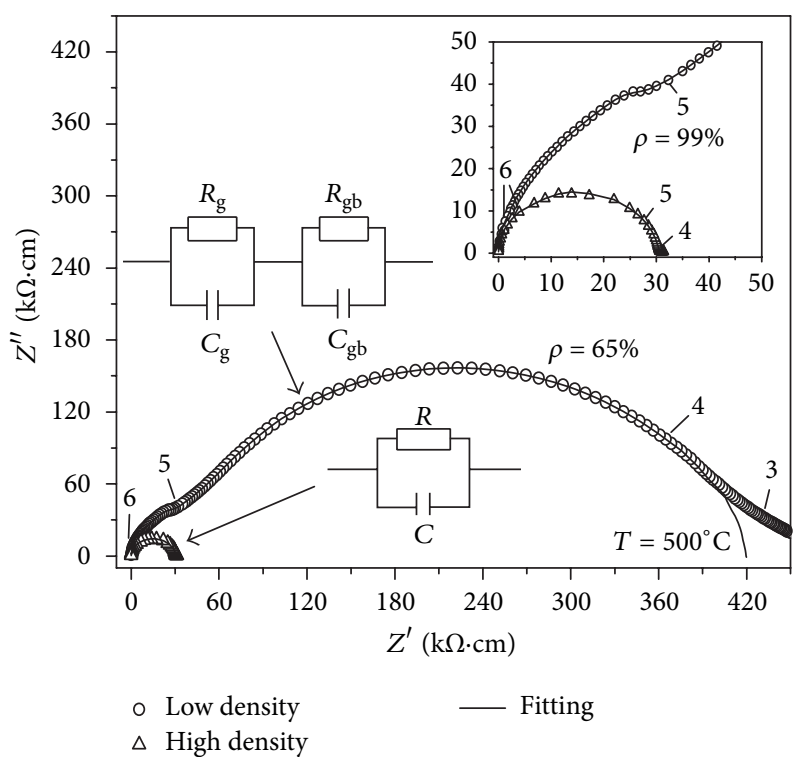

FIgURE 6: Complex impedance diagrams of low- and high-density BTO ceramics, measured at $500^{\circ} \mathrm{C}$. The numbers indicate the log of the signal frequency. The equivalent circuit used for low-density ceramics has separate contributions of grain $(\mathrm{g})$ and grain boundary (gb). For the high-density ceramic, only one RC block was used in the fitting. The solid curves correspond to the overall fitting curves.

the $\log$ plots of $\sigma$ as a function of the reciprocal temperature, for temperatures between $300^{\circ} \mathrm{C}$ and $700^{\circ} \mathrm{C}$. Electrical properties of BTO single crystals were previously reported in [4], and the typical values are included for comparison in Figure 7. It can be observed that the conductivity of the high-density ceramic, as well as the intragrain conductivity of the low-density ceramic, is comparable to that observed

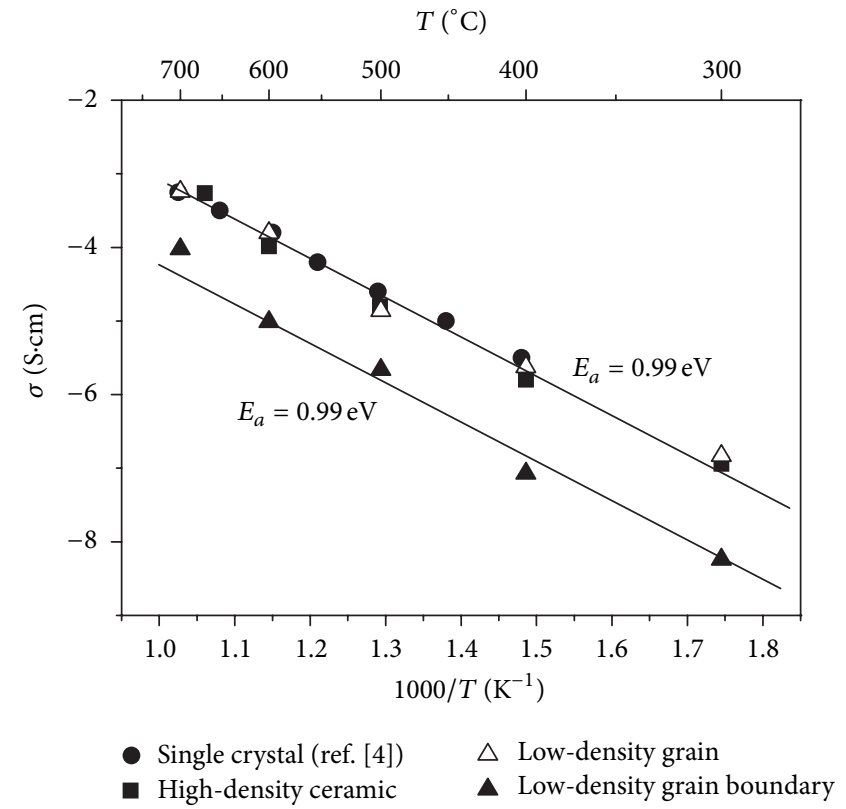

FIGURE 7: Arrhenius plots for ac conductivities in BTO. The apparent activation energy indicated in the graphic was deduced from the slope of the linear regression of the data.

for the single crystal, while the grain boundaries of the lowdensity sample are less conductive. It was also verified that $\sigma$ was thermally activated according to the Arrhenius law:

$$
\sigma=\sigma_{0} \exp \left(\frac{-E_{a}}{k T}\right)
$$

where $\sigma_{0}$ is a preexponential factor and $E_{a}, k$, and $T$ represent the apparent activation energy for conduction process, Boltzmann's constant, and the absolute temperature, respectively. For all the fittings shown in Figure 7, the activation energy 


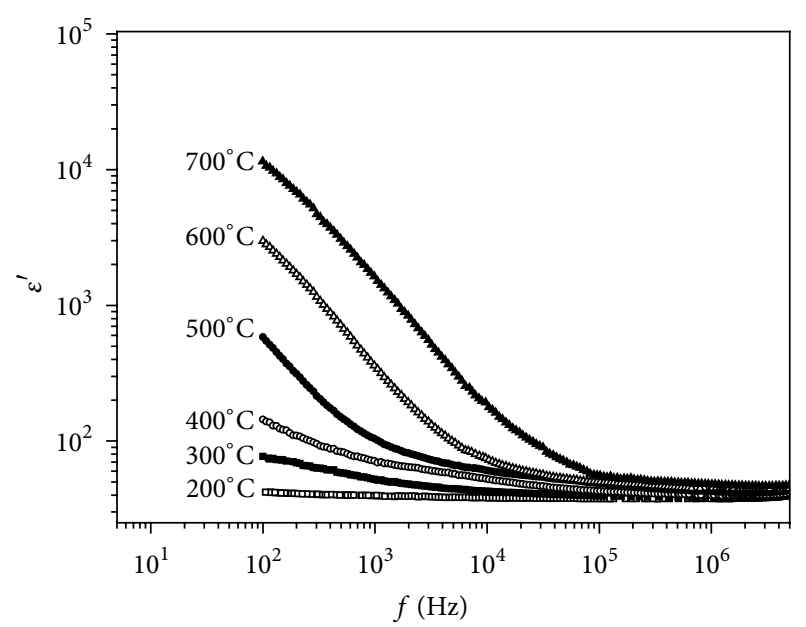

(a)

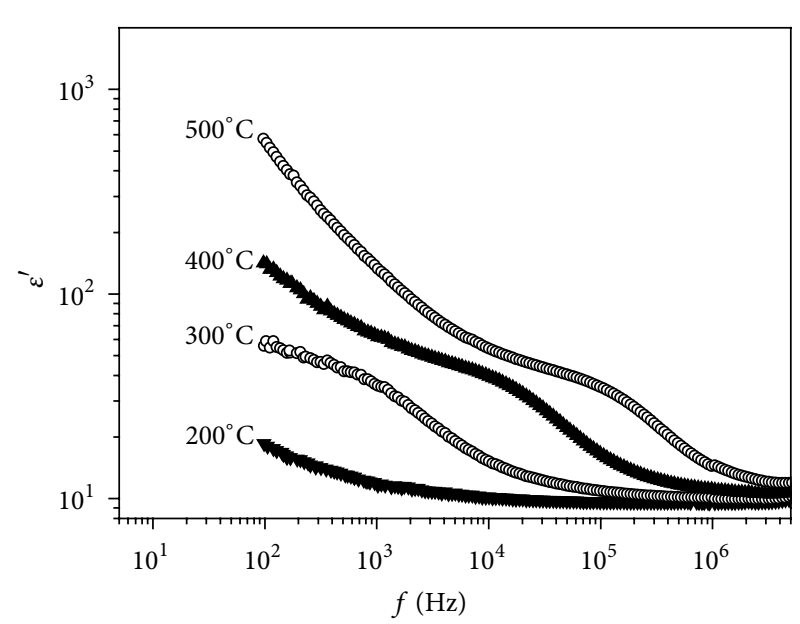

(b)

FIGURE 8: Real part of permittivity $\varepsilon^{\prime}$ as a function of frequency at several temperatures for BTO ceramics: (a) high-density sample and (b) low-density sample.

was determined as $0.99 \mathrm{eV}$. According to the computer modeling of $\mathrm{Bi}_{12} \mathrm{TiO}_{20}$, the most probable intrinsic defects in $\mathrm{BTO}$ are Schottky-type, $\mathrm{Ti}_{\mathrm{Ti}}+2 \mathrm{O}_{\mathrm{o}} \rightarrow 2 \mathrm{~V}_{\mathrm{o}}^{* \bullet}+\mathrm{V}_{\mathrm{Ti}}^{\prime \prime \prime \prime}+$ $\left(\mathrm{TiO}_{2}\right)_{\text {surf }}$, possibly favoring conduction by oxygen migration [21]. On the other hand, EPR measurements indicated the presence of hole centers in BTO, possibly arising from antisite defects $\mathrm{Bi}_{\mathrm{Ti}}^{\prime}+h^{\bullet}[22]$, which would result in electronic $\mathrm{p}$ type conduction. According to our results, both hypotheses are plausible, but the remarkable fact is that $E_{a}=0.99 \mathrm{eV}$ determined for high density of BTO ceramics is the same as reported previously for single crystals [4]. Additionally, the same charge transport mechanism was observed for both microregions of the BTO ceramics, regardless of the porosity of the sample. This behavior is different from that observed for other sillenites [23] where the conductivity of grain and grain boundaries presented well distinct activation energies.

Dielectric permittivity can be expressed as a complex number $\varepsilon^{*}$, obtained from the complex impedance $Z^{*}=$ $Z^{\prime}+i Z^{\prime \prime}$ by

$$
\varepsilon^{*}=\varepsilon^{\prime}+i \varepsilon^{\prime \prime}=\left(i \varepsilon_{0} Z^{*}\right)^{-1}
$$

with

$$
\varepsilon^{\prime}=-\frac{Z^{\prime \prime}}{\omega C_{0}\left|Z^{*}\right|^{2}}, \quad \varepsilon^{\prime \prime}=-\frac{Z^{\prime}}{\omega C_{0}\left|Z^{*}\right|^{2}},
$$

where $C_{0}$ is the empty cell capacitance. The real part of complex permittivity $\varepsilon^{\prime}$ is called dielectric permittivity and was used in this work to evaluate the influence of the grain boundaries on the dielectric behavior of high- and lowdensity samples.

Figure $8(a)$ shows a $\log$ - $\log$ plot of $\varepsilon^{\prime}$ as a function of frequency for the high-density BTO ceramic. When measured at $200^{\circ} \mathrm{C}$, the value $\varepsilon^{\prime}=40 \pm 3$ remains constant for all frequencies. This value is in good agreement with [24], which has reported $\varepsilon^{\prime}=47$ for single crystals measured at $T=170^{\circ} \mathrm{C}$ and $f=1 \mathrm{MHz}$. With increasing temperature, a high degree of dispersion in the permittivity occurs at low frequencies. This behavior is generally found in dielectrics in which a conduction mechanism is present [10] and was also reported for BTO single crystals measured within the same temperature range [4]. From these results, it can be concluded that the dielectric behavior of high-density BTO ceramics is very similar to that reported for single crystals, even at low frequencies where the grain boundaries account for the dielectric response. Figure 8(b) presents $\varepsilon^{\prime}$ as a function of frequency for the low-density BTO ceramic. At the frequency values corresponding to the grain boundaries the real permittivity $\varepsilon^{\prime}$ presents a step decrease. This behavior arises from the heterogeneous conduction in the grain and grain-boundary structures, in which the grain boundaries act as an insulating barrier that causes spatial charges. This interfacial polarization is relatively slow compared with other types of polarization (atomic, electronic, or dipolar) and is related to the dielectric properties of the sample at low frequencies [19]. The features of permittivity observed in Figure 8(b) are consistent with the description of MaxwellWagner polarization, also known as interfacial polarization. In fact, the Maxwell-Wagner model is formally identical to the two-element circuit used to fit the experimental data in Figure 7 [11]. At high frequencies, the dielectric response is dominated by the intra-grain contribution. At these frequencies the real permittivity of the low-density BTO ceramic as presented in Figure $8(\mathrm{~b})$ is $11 \pm 2$, which is lower than that determined for high-density samples or reported for single crystal, due to the high porosity of this ceramic.

\section{Conclusions}

Single-phase translucent $\mathrm{Bi}_{12} \mathrm{TiO}_{20}$ ceramics were produced by the first time in the present work. At sintering temperature of $800^{\circ} \mathrm{C}$, little grain growth was observed when the soaking time was increased from $1 \mathrm{~h}$ to $3 \mathrm{~h}$ at this temperature. The samples with density of about $99 \pm 1 \%$ presented good 
optical transmission between 450 and $1050 \mathrm{~nm}$ and electrical and dielectric properties comparable to those observed for single crystals. These results point out high-density $\mathrm{Bi}_{12} \mathrm{TiO}_{20}$ ceramics as potential substitutes for single crystals in applications that do not demand crystallographic coherence.

\section{Acknowledgments}

The authors wish to acknowledge CMNano-UFS for the microscopy facilities and the funding agencies $\mathrm{CNPq}$, CAPES, and FAPITEC/SE for the financial support.

\section{References}

[1] J. Zmija, M. T. Borowiec, A. Majchrowski, H. Szymczak, and T. Zayarnyuk, "Highly photoconducting sillenite single crystals," Crystal Engineering, vol. 5, no. 3-4, pp. 273-282, 2003.

[2] S. Lanfredi and M. A. L. Nobre, "Conductivity mechanism analysis at high temperature in bismuth titanate: a single crystal with sillenite-type structure," Applied Physics Letters, vol. 86, no. 8, Article ID 081916, pp. 1-3, 2005.

[3] J. Frejlich, R. Montenegro, T. O. Dos Santos, and J. F. Carvalho, "Characterization of photorefractive undoped and doped sillenite crystals using holographic and photoconductivity techniques," Journal of Optics A, vol. 10, no. 10, Article ID 104005, 2008.

[4] S. Lanfredi, J. F. Carvalho, and A. C. Hernandes, "Electric and dielectric properties of $\mathrm{Bi}_{12} \mathrm{TiO}_{20}$ single crystals," Journal of Applied Physics, vol. 88, no. 1, pp. 283-287, 2000.

[5] G. C. Valley, M. B. Klein, R. A. Mullen, D. Rytz, and B. Wechsler, "Photorefractive Materials," Annual Review of Materials Science, vol. 18, pp. 165-188, 1988.

[6] J. F. Carvalho and A. C. Hernandes, "Large $\mathrm{Bi}_{12} \mathrm{TiO}_{20}$ single crystals: a study of intrinsic defects and growth parameters," Journal of Crystal Growth, vol. 205, no. 1-2, pp. 185-190, 1999.

[7] B. Joshi, H. H. Lee, Y. H. Kim, Z. Y. Fu, K. Niihara, and S. W. Lee, "Hot pressed translucent (Mg,Y)-alpha/beta-Sialon ceramics," Materials Letters, vol. 80, pp. 178-180, 2012.

[8] G. Mata-Osoro, J. S. Moya, and C. Pecharroman, “Transparent alumina by vacuum sintering," Journal of the European Ceramic Society, vol. 32, no. 11, pp. 2925-2933, 2012.

[9] Y. Q. Shen, R. Chen, G. G. Gurzadyan et al., "Fabrication and spectroscopic characterization of $\mathrm{Ce}^{3+}$ doped $\mathrm{Sr}_{2} \mathrm{Y}_{8}\left(\mathrm{SiO}_{4}\right)_{6} \mathrm{O}_{2}$ translucent ceramics," Optical Materials, vol. 34, no. 7, pp. 11551160, 2012.

[10] Z. S. Macedo, R. S. Silva, M. E. G. Valerio, A. L. Martinez, and A. C. Hernandes, "Laser-sintered bismuth germanate ceramics as scintillator devices," Journal of the American Ceramic Society, vol. 87, no. 6, pp. 1076-1081, 2004.

[11] J. R. Macdonald and E. Barsoukov, Impedance Spectroscopy Theory, Experiment, and Applications, Wiley \& Sons, New Jersey, NY, USA, 2005.

[12] Z. S. Macedo, C. R. Ferrari, and A. C. Hernandes, "Impedance spectroscopy of $\mathrm{Bi}_{4} \mathrm{Ti}_{3} \mathrm{O}_{12}$ ceramic produced by selfpropagating high-temperature synthesis technique," Journal of the European Ceramic Society, vol. 24, no. 9, pp. 2567-2574, 2004.

[13] Z. S. Macedo, M. H. Lente, J. A. Eiras, and A. C. Hernandes, "Dielectric and ferroelectric properties of $\mathrm{Bi}_{4} \mathrm{Ti}_{3} \mathrm{O}_{12}$ ceramics produced by a laser sintering method," Journal of Physics Condensed Matter, vol. 16, no. 16, pp. 2811-2818, 2004.
[14] Z. S. Macedo and A. C. Hernandes, "A quantitative analysis of the laser sintering of bismuth titanate ceramics," Materials Letters, vol. 59, no. 27, pp. 3456-3461, 2005.

[15] T. M. Bruton, "Study of the liquidus in the system $\mathrm{Bi}_{2} \mathrm{O}_{3} \mathrm{TiO}_{2}$," Journal of Solid State Chemistry, vol. 9, no. 2, pp. 173-175, 1974.

[16] E. I. Speranskaya, I. S. Rez, L. V. Kozlova, V. M. Skorikov, and V. I. Slavov, " $\mathrm{Bi}_{2} \mathrm{O}_{3}-\mathrm{TiO}_{2}$ system," Izvestiya Akademii Nauk SSSR, Neorganicheskie. Materialy, vol. 1, no. 2, pp. 232-235, 1965.

[17] S. Miyazawa and T. Tabata, " $\mathrm{Bi}_{2} \mathrm{O}_{3}-\mathrm{TiO}_{2}$ binary phase diagram study for TSSG pulling of $\mathrm{Bi}_{12} \mathrm{TiO}_{20}$ single crystals," Journal of Crystal Growth, vol. 191, no. 3, pp. 512-516, 1998.

[18] D. C. N. Swindells and J. L. Gonzalez, "Absolute configuration and optical activity of laevorotatory $\mathrm{Bi}_{12} \mathrm{TiO}_{20}$ " Acta Crystallographica Section B, vol. 44, pp. 12-15, 1988.

[19] J. Yu, P.-F. Paradis, T. Ishikawa, and S. Yoda, "Maxwell-Wagner effect in hexagonal $\mathrm{BaTIO}_{3}$ single crystals grown by containerless processing," Applied Physics Letters, vol. 85, no. 14, pp. 28992901, 2004.

[20] L. M. Nunes, E. Antonelli, M. I. B. Bernardi, T. O. Oladeinde, J. A. S. Caceres, and J.-C. M'Peko, "How grain boundaries modify the high-temperature dielectric response of ferroelectric electroceramics like $\mathrm{BaTiO}_{3}$ ?" Materials Research Bulletin, vol. 46, no. 1, pp. 136-139, 2011.

[21] R. A. Jackson, J. A. Dawson, M. E. G. Valerio, and Z. S. MacEdo, "Computer modelling of $\mathrm{Bi}_{12} \mathrm{TiO}_{20}$ : intrinsic defects, ion migration and rare earth ion incorporation," Optical Materials, vol. 32, no. 10, pp. 1375-1376, 2010.

[22] J. F. Carvalho, R. W. A. Franco, C. J. Magon, L. A. O. Nunes, F. Pellegrini, and A. C. Hernandes, "Vanadium characterization in BTO:V sillenite crystals," Materials Research, vol. 2, no. 2, pp. 87-91, 1999.

[23] Z. S. Macedo, C. S. S. Oliveira, and A. C. Hernandes, "Dielectric relaxation mechanism of single crystal and polycrystal bismuth germanate," Journal of Applied Physics, vol. 102, no. 3, Article ID 034105, 2007.

[24] F. Mersch, K. Buse, W. Sauf, H. Hesse, and E. Krätzig, "Growth and characterization of undoped and doped $\mathrm{Bi}_{12} \mathrm{TiO}_{20}$ crystals," Physica Status Solidi A, vol. 140, no. 1, pp. 273-281, 1993. 

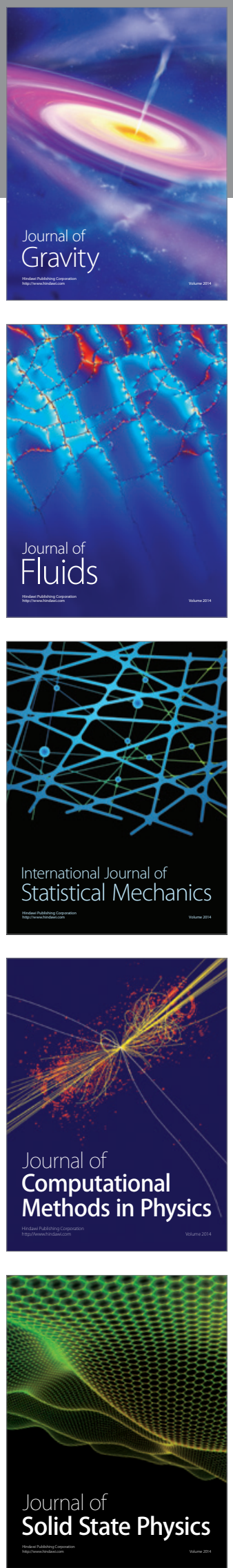

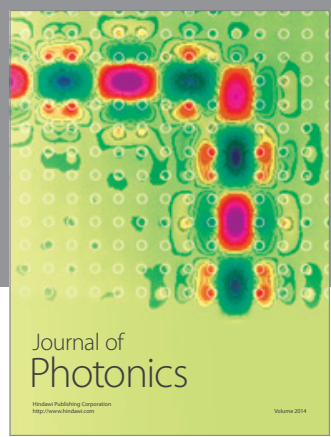

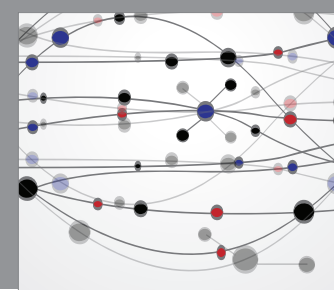

The Scientific World Journal

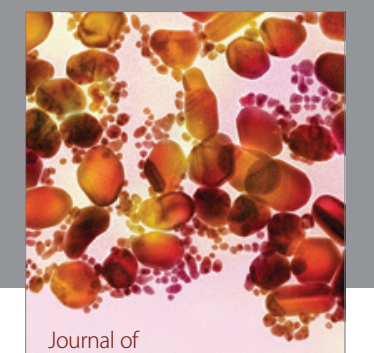

Soft Matter
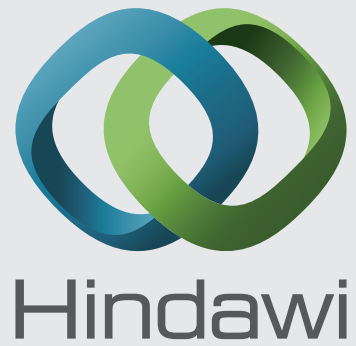

Submit your manuscripts at

http://www.hindawi.com
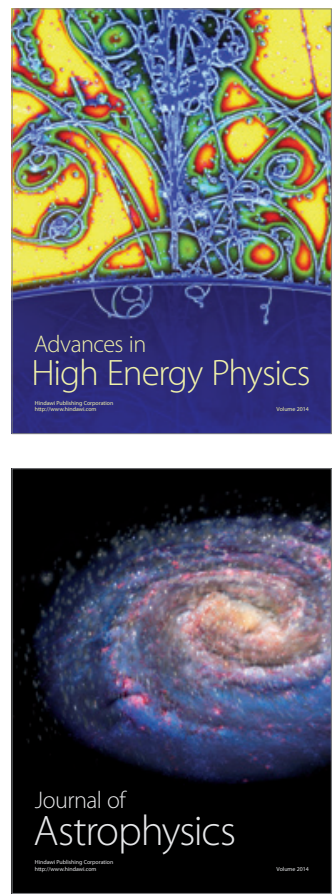
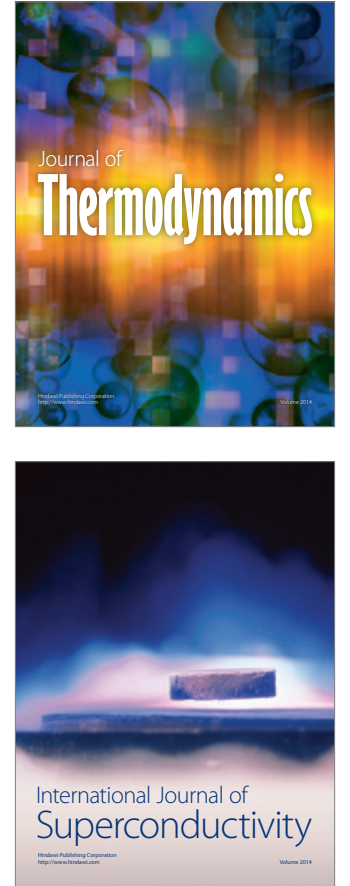
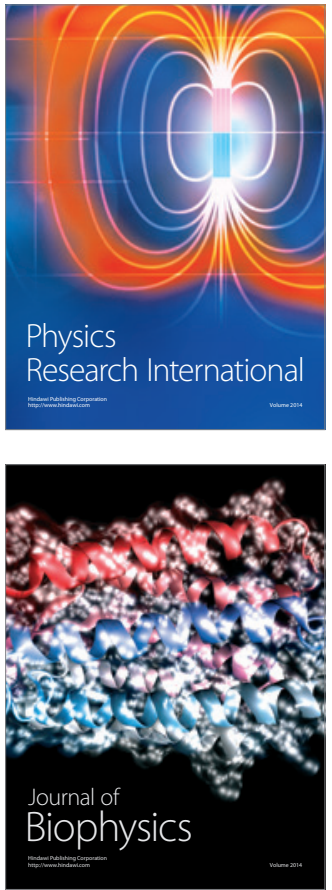
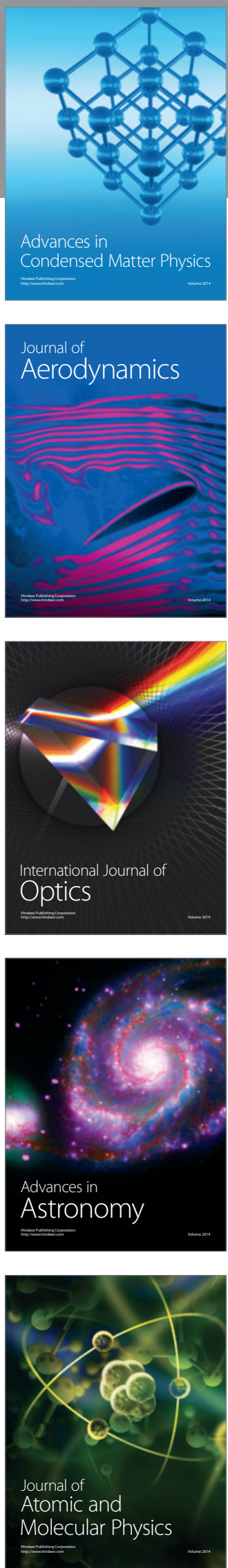